\title{
Practical Rationality - its Nature and Operation
}

\author{
Andrzej Niemczuk \\ University of Rzeszów, \\ Rejtana 16c Av., \\ 35-959 Rzeszów, Poland \\ e-mail: aniemczuk@ur.edu.pl
}

\begin{abstract}
:
The article presents a proposal of explanation what practical rationality is, how it works and what are its criteria. In order to define practical rationality, the author starts from the general characteristics of reason, and then in the realm or reason activity distinguishes practical rationality from theoretical rationality. The necessary conditions of practical rationality are presented, as well as its standing between freedom and values. Next, the sources and nature of practical reasons are characterized, as well as their relation to values and desires. The problem of practical syllogism is briefly commented on. In the final part of the article the author proposes five criteria of practical rationality.

Keywords: practical rationality, reason, practical reasons, criteria of rationality, practical syllogism, freedom, values.
\end{abstract}

\section{General Remarks on the Concept of Rationality}

The typologies of rationality proposed in the literature on the subject are too varied to comment on them in detail in the present article. The differences between them vividly come to light when relevant works by Ryszard Kleszcz, Mieszko Tałasiewicz, Józef Życiński, Ryszard Szarfenberg and other authors are compared [3], [16], [17], [18], [14], [7]. Differentiated types are usually created by adding a domain adjective to the notion of rationality (e.g. epistemic, methodological, ontological, pragmatic rationality etc.), or a noun defining a field of thinking (e.g. rationality of science, politics, common thinking, decision, economic choice, etc.).

Examining these typologies, one finds it difficult not to throw a fundamental doubt whether they meet the requirements of logical division - even in those (rare) cases when they seem to be complete, doubts remain as to their disjunction, their uniform criterion, and the precision of their scope (whether they include in the scope of X something that is not X). These doubts could be ruled out if the authors of these typologies, firstly, at the beginning presented a clear description of what is subsequently to be divided into types, i.e. rationality itself, and secondly, if the reasons for distinguished types were derived from individual characteristics of the differentiated general rationality. Meanwhile, it is almost a rule in the proposed typologies that although the types are analysed in great detail, it is not characterised almost at all what they are types of (totum divisionis), while the reason for specifying such and no other types is not substantively justified, but accepted only on the basis of random, customary divisions, applied to interlocking spheres of thought. These not quite methodological strategies of creating various typologies of rationality observed here can even be ironically described as insufficiently rational. It is hard to resist the conclusion that as a 
result of such a method of multiplying various types, there are far too many of them. To ask rhetorically: how can one justify the differences (and disjunction!) between such types of rationality as conceptual, logical, methodological, and scientific rationality?

An example of general methodological shortcomings in the construction of typologies of rationality can be the puzzling fact that the author of the broadest study on this subject only at the end of his work (i.e. after characterising various types of rationality) comes to the conclusion that there are meta-principles of rationality which satisfy - as the author writes - "the need for the existence of certain universal criteria of rationality" [3, p. 113]. The text indicates that these metaprinciples identify rationality as such - and therefore, as must be inferred, they must appear in each of its differentiated types, because otherwise the type in which not all of them would be present would be differentiated in an erroneous way. I am not making any accusation here against establishing such meta-principles; I merely wish to point out that their articulation was indispensable as a factual basis for the types distinguished. If the types were distinguished in an $\mathrm{ad}$ hoc manner (without referring to the rules determining rationality), then after revealing these principles, these types should be re-tested to demonstrate that they are types of rationality, and not of something else. It is also not known why the established principles have the characteristics of meta-principles, since they only concern rationality itself. Probably only because the principles previously attributed to individual types were principles of something other than rationality itself which in turn would imply that the types were not types of rationality.

What I am questioning here - namely, the assignment of a separate type of rationality to almost every way of thinking about the world (science, ontology, epistemology, economics, common thinking, etc.) - seems to be just as unjustified as distinguishing as many types of truth as there are disciplines in which it is present, or as many types of life as there are species of organisms. In all these cases, distinguishing between types is undoubtedly correct - in each of them, however, the identification of the "medium" (or subject) of types is incorrect. If, after all, rationality occurs in $\mathrm{X}$ as well as in $\mathrm{Y}$, only its variables change (the kinds of particulars to which it applies), and it itself - as long as it is rationality - remains the same.

Confining myself to this general critical remark against the known typologies of rationality, I would like to add, as a positive proposition, that the question of typologies can, in my opinion, be arranged in the following way. Two types of rationality that should be distinguished - cooperating with each other, but irreducible to one another - are theoretical (or cognitive) rationality and practical rationality. Theoretical cognition of the world and practical functioning in it constitute, on the one hand, the two most general ways of activity of the same reason, and on the other - ways that are so distinct that there are strong reasons for treating them as truly different types of this activity. On the other hand, the numerous types of rationality distinguished in the literature on the subject, which I mentioned earlier, are, in my opinion, models of criteria of justification (or correct argumentation) used in various fragments and disciplines of theoretical knowledge and practical thinking - and in fact there can be as many such models as there are areas in which the ways of justification specific for them were formed. The approach proposed here, on the one hand, gives justice to a certain factual multiplicity (multiplicity of ways of justifying), and on the other, it does not break up rationality to such an extent that the existence of its permanent core becomes doubtful - and therefore there is no need, in order to defend this core, to create additional meta-principles of rationality with their problematic reference to lower (type-specific) principles.

The subject of my further discussion will be only practical rationality - or rather its very essence, described by typologists of rationality, probably interchangeably, as axiological rationality, rationality of values or rationality of goals. I call axiological rationality the core of practical rationality, because I think - contrary to the previously mentioned typologies - that the so-called instrumental (or pragmatic) rationality is in fact not rationality, but only a fragmentary sphere of practical justifications, which (or more precisely: their assumptions) must be consistent with axiological rationality in order to be rational. There are no reasons to consider the selection of effective acts and measures leading to irrational goals as rationality. After all, if someone stuck to a false conclusion and then developed (equally false) premises to go with it in order to obtain a logically correct consequence, then his or her reasoning would not become true. 
Axiological rationality is usually neglected by theorists of rationality (mentioned, but not explained in more detail) because its essence is inseparably entangled in the fundamental problems of axiology, which the researchers of rationality do not want to be concerned with. For the same reason, axiologists and ethicists formulate many important, though usually not systematised, conclusions about axiological rationality as it were on the outskirts of their normative theories. On the problem map of philosophy, the topic discussed in the present article is located in the region where theory of rationality and theory of values overlap. The need to address this borderline topic is dictated by the aforementioned circumstance which consists in the fact that, briefly speaking, although both neighbouring fields, i.e. the theory of rationality and the theory of value, need a systematic theory of their common borderland, today's highly specialised competences of researchers leave this borderline highly undetermined.

As far as the concept of rationality itself is concerned, I think that there are no sufficient reasons to distinguish and separate it from the concept of reasonableness. Therefore, I understand rationality as a field of the functioning of reason. It can therefore only characterise the activity of such entities that have the capacity of reason. Therefore, strictly speaking, they can also think and act irrationally. ${ }^{1}$ The natural world, on the other hand, can be neither rational nor irrational contrary to the ideas of the so-called ontological rationality. On the other hand, reason itself is the highest thinking ability we know. It is people and people only that are entitled to it - as it is closely related to self-awareness, self-knowledge, and reflexivity. The term "the highest ability" means that reasoning is directed primarily toward a lower type of thinking, i.e. toward thinking focused on external reality (or on the empirical). This reflective and meta-level nature of reason determines the fact that it is the source of doubts, criticism, and the idea of justification - both the requirement of justification itself and the creation of justifications, as well as the construction of the theory of justification. Therefore, rationality and justification seem to be the same.

These several features of reason suggest that - as in German philosophy - perhaps reason should be distinguished from the lower ability to think, which would be intelligence or intellect. This lower type of thinking would be responsible for using conceptual contents regarding empirical phenomena and links between them, but without reflective questions about justification. The main difference between reason and intellect would be - if such a distinction is accurate - that intellect amounts to thinking which functions as the subject dictates it and in order to serve his or her vital interests (it performs instrumental-adaptive functions), and reason, as reflective meta-thinking, has at its disposal - as Thomas Nagel called it - "a view from nowhere," which means that: (a) on the part of the subject, it is not determined in terms of its content by the psycho-vital sphere, (b) and in turn its object are the limits of intellectual thinking, or the subjective conditions and assumptions of this thinking, as well as what is ultimate on the objective side of intellectual thinking. Therefore, rational thinking, in a natural way for itself, gravitates in the sphere of theory towards epistemological and metaphysical issues, and in practical thinking - towards philosophy of freedom and philosophy of values (or the theory of good).

In order to answer the question about the participation of reason in scientific knowledge (in empirical sciences), one should carefully examine the logical structure of scientific theories and the history of particular sciences, and only on the basis of these studies determine (a) to what extent sciences go beyond recognising correlations between facts (i.e. beyond the procedures of intellect), and (b) how the ways of justifying the claims of particular sciences, distinctive for these sciences, were historically shaped in them. Such an analysis of science is, of course, a separate problem, and here I merely want to point out that in the scientific thinking there is as much reason as there is reflection on justification. I suppose that both the origin of sciences and their prevailing part which constitutes empirical knowledge are rooted in the intellect, and only the historically increasing requirement of justifying scientific knowledge, the need to reconcile its various fragments, and, finally, philosophical reflection on its non-empirical assumptions, included in it the participation of strictly rational thinking and expanded it. 


\section{Identification of Practical Rationality}

Since practical rationality is a rationality, it has some features in common with theoretical rationality, but, in turn, as a practical one it also has properties that distinguish it from the theoretical one.

I have already mentioned the common features. They are namely: (1) metal-level thinking that is autonomous in relation to psycho-vital reasons; (2) the ability to doubt (that is, to question empirical data and conclusions obtained as a result of intellectual thinking); (3) looking for justifications for lower levels of thinking and reflective revision of the assumptions of this thinking; (4) not yet mentioned here, the use of the basic laws of logic (the law of identity, of contradiction, and of excluded middle).

In order to determine the practicality of rationality, categories that identify practice as such (i.e. the specificity of practice) should be distinguished. Practice differs - it can be said: categorially - both from theory and from processes of nature. In contrast to theory, or even to the process or operation of theorising, it is a sequence of changes not only related to thought (and even less is it a system of claims), but it consists in real changes that modify the real course of events. However, these changes - this time unlike natural changes - are not just a consequence of causes and effects, but are initiated and led by consciousness (although in terms of energy they are performed by the body of the acting subject). Thus, practice is a series of changes in the real world, but initiated and directed by consciousness. ${ }^{2}$

I will disregard the question of the difference between practice and natural processes, since the identification of practical rationality (to which I am leading up to) requires a differentiating juxtaposition of practice and theory rather than of practice and nature. More specifically, it is about capturing the most general differences between how consciousness functions in the mode of theorising and how in the modus of practice.

In both these fields - theory and practice - consciousness seems to have three levels. In the field of theory, these are: sensory perceptions providing content for thinking, intellect (which thinks about the connections between the contents of perception using language and concepts), and reason, which in turn, as meta-level thinking, problematises and fills with the content it constructs both the objective and subjective limits of intellectual thinking, at the same time going beyond these limits. In this way, reason in theory produces - speaking in historical order - metaphysical and criticalepistemological issues. It constitutes meta-empirical thinking in the sense that it directs its questions and answers towards the non-empirical conditions of the empirical. Of course, philosophy is not the only manifestation of reason. In everyday life (as well as in non-dogmatic religious speculations) its activity is expressed in questions and hypotheses concerning what is ultimate (including those, of course, which concern reason itself).

In the practical function of consciousness, the first level consists of positive and negative drive and emotional reactions. Their contents are - one could say - empirical data for practical thinking. In turn, the intellect in the practical function is thinking which, basing on the recognised correlations between objects of emotions, selects the ways of instrumental actions. These actions are admittedly intelligent (and not spontaneously emotional), but the intellect that designs them remains instrumental thinking, because, firstly, it is itself guided by psycho-vital dynamics and, secondly, its calculations are limited to the ways of avoiding discomfort and satisfying desires imposed on it by the leading emotions. This is because the practical intellect does not keep a cognitive distance from the subject's own desires and emotions (they are not an object for it), so it also does not evaluate them, but functions as an instrument of their implementation. Therefore, the goals pursued by it are not critically selected and therefore they have no other justification than the very fact of their energy advantage over the tendencies that are weaker in a given situation. In other words, practical intellect only plays the power game of fears and desires that takes place behind its back. It is not familiar with freedom of thought and reflection on justification.

The meta-thinking of reason becomes practical when the subject seeks justifications for his or her future practical activities, but with the assumption that he himself or she herself is their free agent. If he or she understood his or her future actions as necessary cause and effect chains, he or she would not be able to ask for their justification. We can see, therefore, that when asking for the 
justification of its future practice, practical reason not only thereby assumes its own freedom, but at the same time challenges what is an uncritical assumption for practical intellect - namely, it questions the treatment of psycho-vital desires as sufficient reasons for the undertaken actions. It is also worth noting that if the subject did not assume freedom and understood his or her future deeds as the necessary effects of his or her psycho-biological desires, it would mean that he or she does not understand his or her future as a practice they pursue, but as a natural process that does not have an author. In this understanding of one's own future, practical reason would destroy itself - it would be pointless. Such self-destruction of practical reason takes place - I believe - in every determinist who, if logically consistent, must translate his or her life only in the perspective of theoretical reason.

On the basis of the above, it must be stated that for practical reason the assumption of the existence of one's freedom is a sine qua non condition of its functioning - without this assumption, all its operations would be based on a fundamental internal contradiction (and thus they would lead to self-destruction).

Freedom, however, is not just independence from causes. For a rational being to be able to initiate and pursue practice as a free activity, he or she must have a positive justification for his or her actions, other than psycho-vital causes (if they were the only determinants of action, it would not be free - so they would not be practice). Practice therefore requires not only that its beginning is independent from causes, but also requires positive determinations that are different from these causes. Without them - so to speak - independence itself would not move off, and practical reason would still have no object. These practical determinations are practical reasons. Reasons, in turn, can neither have no object (they would not be reasons then), nor can their objects be facts, beings, or laws of nature - because then they would not be of practical but of theoretical nature and nothing would result from them for practice. It therefore remains to accept that values are objects of practical reasons.

If, therefore, we call practical rationality - as I suggest - the functioning of reason that directs practice, we can already mention its two necessary conditions. The subjective condition is freedom, while the objective one - values. On the other hand, practical rationality itself consists of practical reasons, and it enters real practice in the form of decisions.

Reasons are something other than causes, so - what should be emphasised - only acting on the basis of reasons makes this action free. It seems that this issue needs to be interpreted more precisely as follows: the very fact of consciousness makes a person negatively free and, thanks to that, enables positive freedom of decision and action - but only enables it! And only adding something positive to negative freedom - something that "launches" a decision independent of the causes - completes the negative aspect of freedom with a positive aspect (and only then does a person perform a free deed). This positive factor which triggers action and at the same time preserves its freedom is either a single reason or, generally speaking, practical rationality. This means, first of all, that rationality, and also positive freedom with it, are not, like consciousness, facts that occur in people, but that they are normative tasks (which are sometimes achieved and sometimes not) for the consciousness which has a much wider scope than them. Secondly, it also means that only practically rational action is free action - while irrational action, even if its beginning was negative freedom, slides into causal determination. On the other hand, since practical reasons are related to values, it follows from the above diagnosis that free action is impossible without values (i.e. practice is impossible).

To conclude the presented argument in the simplest way possible, it can be stated that in order to act in a free way, one must be rational in a practical way; rationality in turn depends on the proper respect for and selection of values. The problem of values cannot be overlooked here. Explaining what values themselves are, I will introduce, in addition to freedom and values, a third category necessary to identify practical rationality - the category of happiness.

Values as objects of practical reasons can neither be subjective creations of desires nor any kind of objectively existing entities. Both of the interpretations of values mentioned here - in brief fall into the naturalistic fallacy and are irreconcilable with the necessary assumption of freedom of practice. $^{3}$ Any attempts to explain practice that do not take into account freedom as its source must become trapped within the limits of theoretical-descriptive thinking about reality (and about the 
practice itself, which is then only alleged), and there is no logical transition from such thinking to a normative discourse. The assumption about the existence of freedom (or the point of view of freedom) sets - as it seems to me - the only perspective in which one can sensibly talk about values. "Sensibly" means here neither falling into the naturalistic fallacy nor (by reducing values to the ontic causes of action) denying freedom. Only then is practical rationality not reduced to theoretical one.

In order for values and freedom not to exclude one another, and for the former not to reduce themselves to the realm of beings, they must be interpreted as something which in the face of freedom is its necessary complement (and not an antagonistic factor). Values are indispensable for freedom in the sense that freedom cannot survive real changes without them (i.e. it cannot retain its self-continuation). For if the change taking place in a person is not directed by free affirmation of some value, then this change is determined by causes, degrading the human being to the position of a multiple-conditioned automaton. It means that a person cannot preserve their freedom in any other way than through the affirmative recognition of values. Only such affirmation makes it possible to set oneself and to achieve a goal alternative to what would emerge from an inert cause-effect sequence. Values are therefore objective conditions of the persistence of freedom - after all, freedom is not a substance that could last independently of the changeability of the world. But they can be non-threatening to freedom only when they are dependent on it themselves - when it establishes their validity. What are values, then?

My construction of the philosophy of values - in brief - is as follows [11]. The sphere of values and the sphere of beings are objectively one and the same reality. And what requires their differentiation are different points of view of the same reality. Different points of view also force the use of different concepts in relation to the aspects of one reality determined by these points of view. From a theoretical point of view, reality is a sphere of beings without values. On the other hand, from a practical point of view - in other words, from the point of view of freedom - reality, in turn, is not the domain of beings but of valuable objects.

My answer to the question where the valence (or the axiological significance) of existing objects comes from is as follows: its source is the absolutely first free decision of the existing subject - not the first in chronological terms, but logically, i.e. the one whose content is logically first in relation to the content of all other decisions. Its primary nature consists in the fact that the subject chooses in it not these or other existing objects, but one's own existence in the world. "Own" means here: the existence of oneself as a free subject. In simple terms, reality is valuable only because free subjects want to exist in it, continuing their freedom. This is the basis of my philosophy of values, while the rest of its claims are subtleties and conceptual and logical details; there is no space here, however, to elaborate on them [11], [12]. Let me just mention that in the development of this conceptual and logical instrumentarium, the most important thing is to consistently carry out conceptual analogies between ontological and axiological categories (which I try to show meticulously in my other works). What I consider to be the advantages of this concept is that it does not fall into the naturalistic fallacy (because the source of value is a decision, and not some beings), that it does not reproduce the dualism of being and values, and that it seems to avoid the typical difficulties of axiological subjectivism. However, the burden of explanation shifts to the clarification of differences (and mutual references) between the two above-mentioned subjective points of view. In the area of required clarifications, there is also the question of practical rationality.

Concluding the thread of values, it must also be added that the question of why free beings want to exist (or why their logically original decision is positive) does not seem to have a more accurate answer than the view that philosophy has always held: that the ultimate profit which the subject draws from his or her participation in reality is smaller or greater happiness. And in fact I think that without a concept of happiness philosophy cannot satisfactorily explain values, practice, or even practical rationality. Without referring to this concept (or a synonymous one), there are no good answers to the questions about the first reasons of subjective action. What I have in mind here, for example, are such questions as: why is it better to live than not to live? Why act at all and not remain a drifting object? Why should I be moral? And finally, why is it better to be rational than irrational? If we do not take into account and do not name a specific "profit" which the subject 
receives as a result of the undertaken positive involvements, the fact of these involvements will remain inexplicable and incomprehensible. The category of happiness, being the third - apart from freedom and value - category of practice, is a category that also identifies practical rationality.

As we already have the most important categories of practice at our disposal, we can conclusively distinguish practical rationality from theoretical one - and they differ in almost everything except the presence of attributes of reason in them. While the subject of theoretical rationality is the sphere of beings (or facts), the subject of practical rationality is the sphere of values. While the subject of the former is impersonal reason (impartial, individualised, leaving aside values), called theoretical reason, the subject of the latter is individual freedom existing in the real world, which uses reason to ensure its own persistence in an environment of permanent change. And finally, the third difference concerns objectives: for theoretical rationality, the goal is the universal and impersonal truth of theory (objective knowledge), while the objective of practical rationality is the individual happiness of the subject, obtained as a result of free action directed by values.

\section{Practical Reasons Between Freedom and Values}

I have already mentioned the relationship between practical rationality and freedom: namely, it is two-sided. On the one hand, negative freedom, or independence from causes, is a necessary condition for practical rationality - after all, without this independence, it would be pointless to construct justifications for practical actions (it would only be Marx's false consciousness). On the other hand, only practical rationality complements negative freedom with a positive aspect, that is, it makes it able to perform real actions - for without positive reasons provided by rationality conscious action would either be unable to "move off" or would fall to the level of determined natural processes. The question remains, however, where the contents of practical reasons originate from, since they must refer to values, whereas reality - as I have stated earlier - consists only of beings and not of values.

The contents of practical reasons come from rational affirmation, which the subject's freedom directs towards individual beings as the conditions of his or her existence and happiness. To put it more precisely, practical reasons have three aspects: content, practicality, and rationality. (a) The content itself is a mental correlate of the purely ontic definiteness of something that exists (it is axiologically neutral in itself, as is its ontic counterpart). In turn, the practicality of these contents (and this is what gives them axiological character) comes from the attitude towards the reality of two subjective factors: first, the one that the Greeks called thymos, or the drive and emotional sphere, but to a decisive extent only from the affirmative relation to freedom. Their rationality, on the other hand, consists in the fact that they are interrelated in a logically correct manner and that they are justified by reason (which is why they are reasons, not just motives or desires).

To explain briefly the constitution of practical reasons, one can refer to the known figure of the so-called practical syllogism (formulated by Aristotle and developed by John Stuart Mill, as well as Donald Davidson). ${ }^{4}$ It is known that the scheme of this syllogism shows that an individual imperative conclusion results deductively from the general greater imperative (or value) premise and from at least one lesser descriptive premise accompanying it. Practical reasons are what I call these larger value premises and the above-mentioned imperative conclusions. The deepest problem (which was not solved satisfactorily by Aristotle or the subsequent researchers of practical syllogism) concerns the sources of the greater premise which would be the absolutely first and not one of intermediate greater premises. It is obvious that this absolutely first axiological premise must concern what distinguishes the entire domain of values from the domain of being that is not concerned with values. It is easy to guess that in the light of what I have stated earlier, this absolutely first premise originates from the logically first decision of the subject, in which his or her freedom affirms his or her existence. Because of the primary nature of this decision, I call it the primaeval decision. Because the subject cannot exist without the world, the practical choice of one's own existence is identical with the affirmation of existence in general. Therefore, the primaeval decision establishes the first practical reason, which is the first axiological premise for all 
other practical reasons, narrower in their scope. The simplified content of this first premise - its very essence - is as follows: "existence is valence." The former theory of transcendentals expressed it in another version: "existence is goodness."

Before I show a manner of particularising (i.e. a differentiating fragmentation of content) of this first practical reason, I would like to point out that it constitutes the basis of general axiology. Since existence is valence, it follows - analogically to ontological inferences - that specific existing beings are valuable objects. But because their axiological positivity is constituted by the affirmative primaeval decision of the subject, the values that they are entitled to are not - strictly speaking their own qualities (such as ontic properties), but their relations to the freedom and happiness of the subject. They are practical relationships, expressed in conceptual discourse with practical categories. Depending on how we logically classify these practical relationships, we will obtain different sets of axiological categories, such as: moral value, epistemic value, aesthetic value, vital value, hedonistic value etc. However, in order for these relations to remain practical (and not ontic), that is, to remain values (and not beings), they must be sustained on the part of freedom via practical rationality. This means that even such unreflective and spontaneous relations as e.g. hedonistic values change from facts into values only once practical rationality affirms them or approves them. It is only when they obtain a practical reason that they become values. ${ }^{5}$

However, while addressing the problem of how the first practical reason is divided into a multiplicity of reasons with a smaller scope, one must already refer to the actual diversity existing in reality. Three circles of diversity are in question here: (a) the multiplicity of subjective desires; (b) the multiplicity of objective things and events; and (c) the multiplicity of types of practical action (this multiplicity is called a multiplicity of practices by e.g. Alasdair MacIntyre [6, pp. 7-10, 340-364]). These three areas of multiplicity concretise and differentiate the content of practical reasons, which makes it possible, firstly, to make specific decisions, and secondly, to apply practical rationality in these decisions.

When describing the nature of practical reasons, it is worth emphasising that their very (previously explained) content is powerless in the sense that thinking it is not able to cause decisions or actions in the subject. This is consistent with the fact that this content is axiologically neutral (a) as long as the subject does not want to continue his or her own existence, and (b) until he or she notices and understands the relationship between the content and his or her own existence. The content of reasons, on the other hand, obtains the power to determine the actions of the subject only when the two aforementioned circumstances change into positive ones - that is, when the subject maintains his or her primaeval decision and when he or she applies practical rationality. It is then that he or she gives the powerless reasons a practical character, and thus the power to direct action. The power of these reasons ultimately comes from the subject's primaeval decision. In the field of practical rationality, the following principle applies: that for some reason to be able to cause an act of the subject, it must - assuming the rationality of the subject - have a logical connection with the content that the subject already wants. If he or she did not want anything, then no reason would have a causative power for his or her action - and that would mean that it would not be a practical reason. For example, a reason that claims that one should pass another exam at university overcomes the psychological reluctance to learn once the student realises the necessary connection between passing the exam and his or her own desire to obtain a diploma. If this willing was not in the subject, this example of a reason would not move him or her.

Constituting practical reasons by some willing that is more primal than them (it can be called the involvement of the subject in reality) and thus establishing their binding character is what distinguishes them from theoretical reasons. In order for a judgement to be a practical reason, neither its imperative grammatical form nor the logical correctness of its connections with the system of similar judgements is sufficient. In order for imperative judgements of a certain internally coherent system to be practical reasons, at least one of these judgements must be connected with the real subject in such a way that the content of this judgement is both the content of the subject's act of willing - and it has to be free willing (non-free willing is not willing, but only a causally created fact of desire). Since imperative judgements do not result from judgements about reality, then any their logical system remains non-binding for the subject - that is, it is not a system of reasons until the content of any of the judgements is the content of the subject's decision. 
However, when a subject wants to decide something in a free way, the freedom of his or her decision depends on whether it is rational - and it is rational when its content is not contradictory both with its more general premises and its more detailed logical consequences. Therefore, for the subject to make one free decision, he or she must at the same time decide on the correctness of an entire system of imperatives which is affirmed by this one decision. If the system contains the imperatives A. B, C, D, etc., then the subject cannot choose for example the imperative C, and reject the others - as then his or her decision, not being rational, would not be a decision.

So if the content of a decision of his or hers (such as the decision to enslave another person) was contrary to the fact that he himself or she herself lives and makes decisions - that is, accepts an imperative affirming the value of subjective, free life - this decision would not be rational. In order to make it rational, he or she would have to cancel his or her decision affirming his or her own life and freedom (i.e., adopt other imperative assumptions) - and then, of course, he or she could not do anything.

In contrast to practical reasons, the binding nature of theoretical reasons is not rooted in the decisions of the subject, but comes either from the principles of logic or from empirical evidence. Consequently, for a theory to be true, the subject's consent is not needed. If the individual subject does not agree with the real theory, then it does not lose out, but he or she does. On the other hand, in the case of validity of imperatives, it is a bit different: as long as inconsistency in the decisions of the subject is fragmentary (local), then this circumstance is devaluing for the subject, not for imperatives (just as in theoretical thinking), but if the subject cancelled his or her primaeval decision - if he or she freely refused to continue his or her being a subject - with such lack of a positive primaeval decision there would not exist any practical reasons that would be binding for him or her. In other words, the possible lack of a positive primaeval decision invalidates, it seems, all systems of imperatives - but it can only happen when this factor occurs, and is the unique factor that can have this effect. Taking the positive primaeval decision as the basis, the difference between practical and theoretical rationality can be concluded as follows: ignoring practical reasons causes in the subject a deficit or complete loss of freedom and happiness, while failing to respect theoretical reasons - as long as they are not related to the personal situation of the subject - only puts him or her in the state of ignorance or cognitive error.

\section{The Functioning of Practical Rationality and its Criteria}

The area to which practical rationality applies and where it operates is the area of the subject's desires and their references to objective reality - desires are in fact the driving forces of action. The purpose of its functioning is the permanent ordering of relations between desires and reality namely, such ordering that would be correct in terms of their compliance with the primaeval decision and the subject's endeavours to maintain and increase happiness (i.e. to achieve practical effectiveness). If we treat happiness as a reason of the primaeval decision - and I think that its role in the structure of practical rationality should be understood in this way - then we can define this rational correctness of desires as a reconciliation of their multiplicity with the first principle of practice established by a single primaeval decision. Since the area of concern of practical rationality are the relations of desires to the objective world, it ensues from it that the domains from which it must derive its contents are the sphere of subject's self-knowledge and the sphere of descriptive (scientific and ontological) knowledge about the objective world. Adding axiological reasons logically consistent with the first practical reason - to both these spheres from the outside, practical rationality transforms the facts occurring in these spheres into valuable objects. Axiology - if I could allow myself an aphorism - is rationality imposed on the real world by freedom, which wants to satisfactorily persist in it.

It can be said that in relation to desires, practical rationality functions in two ways: it appears that it is more often inhibitory and sometimes generative. There are always more such facts as desires in the subject than rational desires - that is why conclusions from practical reasoning hold back most desires and allow only those to function which have gained the approval of rationality. This happens more or less in the same way as when Leibniz's God chose one of the many possible worlds to be created - all "strove for existence" $[5,485]$ but God did not stop the existence of only 
that which was considered the best by God's reason. But it also happens the other way round; namely, it is only an imperative conclusion (some individual practical reason) that generates an individual desire which - although it was not present in the subject - after reasoning becomes the motive of the deed. This is always the case when the current empirical situation rationally forces the subject to - for the purpose of achieving the intended general goal - do something that he or she does not actually want at the moment (e.g. making an ill and lazy person take up appropriate exercise in order to save their health). It is worth emphasising, however, that even in the latter case, a specific desire is not produced by a reason (a reason only justifies the need to arouse it), but by that desire with a wider scope for whose realisation this individual desire is necessary. This means that in such cases, practical conclusions serve the purpose of concretising the more general content of desires to the form of individual content - and only in this way shape the act of specific desires.

Practical rationality, as meta-thinking about desires and their objects, does not produce desires by itself, but only logically orders their contents. However, in order for this ordering to be practical, it must - as I have already mentioned - use three types of content: (a) the content of the first practical-axiological premise; (b) the contents of psychological desires, (c) the contents that create descriptive knowledge about the world - including the descriptive content of the subject's self-knowledge.

Therefore, the criteria of practical rationality must concern the appropriate composition and interdependencies between these three types of content. Since the criteria are measures of whether given practical reasoning is rational or not, they can be identified with the principles of practical rationality. These are the principles without which rationality simply does not function. They are its foundations or constitutive elements. ${ }^{6}$ At a high level of generality, these criteria can be characterised as follows:

1) The criterion of the affirmation of being. A positive primaeval decision, in which the subject, affirming his or her own freedom and rationality, also affirms the existential conditions of his or her existence, is the criterion of practical rationality in the sense that it provides the first imperative premise without which it could not be decided whether fragmentary practical reasoning and desires themselves are rational or not. The very fact of the occurrence of a desire is not a reason for its legitimacy (rationality). If the imperative premise is necessary for the reasoning to be both logically correct and practical, then it is clear that without it all inferences that would concern action would have to lack either logical correctness or practical character - so they would not be practically rational.

The concepts of axiological rationality which state that the rationality of axiological reasonings (or those concerning goals) consists in their compliance with the values of a given culture or society [3, p. 75], or in compatibility with some facts of nature (e.g. with the human nature or the so-called natural human needs) all fall into the same error. It invariably consists in the fact that such concepts propose recognising as rational such reasoning which logically derives imperatives from descriptive premises - all in all, the invoked measures practical reasoning must be compatible with in order to be rational (whether these are axiological models from a given culture or any qualities of man) are nothing but facts. In view of this kind of concept, the following legitimate question always arises: are the measures which practical reasoning should be compatible with rational themselves?

2) The criterion of criticism and self-knowledge. The shortest explanation is that the principle of criticism is to doubt the legitimacy of one's spontaneous desires and, consequently, test their validity or justify them. The psychological fact of the occurrence of a desire is not in itself rational - this desire can only be considered rational as a result of rationally checking the connections that exist between its content and its general surroundings. In particular, it is about establishing the relation of this single content to: (a) the content of the primaeval decision, (b) the content of other desires, and (c) the knowledge of actual reality. The next criterion (3) determines what kind of these relations makes a desire rational. Self-knowledge, on the other hand, is indispensable not only for a reflective realisation of the assumed primaeval decision, but just as much for knowing what makes us happy and to what extent. By revealing the position of an individual desire in the subjective hierarchy of desires, and thus the degree of its effectiveness for happiness, self-knowledge is also a sine qua non condition of axiological knowledge of the 
hierarchy of values $^{7}$ (see criterion 5). Self-knowledge also protects one from erroneous identification with the desires of others, those promoted by ideologies, advertising, social fashion, or environmental pressures. It can be said that criticism and self-knowledge are an irreplaceable antidote against the threats to rationality that have their sources both in irrational social trends and in the brutal biological-emotional spontaneity, particularly intensified in the period of youth.

3) The criterion of non-contradiction. While the first criterion concerned only the content of the first axiological and imperative premise, and settled the question of its validity for the subject of action, and the second served the purpose of distinguishing desires that are firmly established in the subject and desires that bring him or her happiness from accidental and "mistaken" desires, the present criterion determines the rationality of all contents of desires. Because the required relationship of non-contradiction may exist (or may be missing) in several different areas, the current criterion requires division into relevant regions. And thus, for the content of a desire to be rational, it must be non-contradictory with: (a) the first axiological premise, i.e. with the content of the primaeval decision; (b) with the content of other specific desires, insofar as those are rational; (c) with the content of real possibilities (it cannot concern what is realistically impossible); this principle can be specified by taking into account particular temporal moments: non-contradictory with the present possibilities (relativised to the current situation) or non-contradictory with the universal possibilities resulting from the laws of nature.

Mentioning the requirement of non-contradiction of desires with the content of the primaeval decision, it is also worth commenting on the question of the practical syllogism. The theory of this syllogism proclaims, as it is known, that between the general imperative premise and the detailed imperative conclusion - after adding a relevant descriptive judgement to the former ${ }^{8}$ deductive reasoning takes place. Strictly speaking, such reasoning does not occur for two reasons. First of all, if there is a premise that I want to eat fruit, it does not follow from it that I should eat an apple, but only that I should eat an apple, a pear, a plum, etc. It means that between the general content of the premise and the detailed content of the conclusion there is a gap that the subject fills in with a free choice each time, adapting its content to his or her individuality. And this applies to every stage of concretisation - that is, every transition from any general premise to a specific decision. The second reason for the lack of strict reasoning in the so-called practical syllogism is the nature of descriptive lesser premises. They report, as is known, every empirical situation in which the subject finds himself or herself. Despite the fact that the imperative premise is general, both the subject that employs it and every situation are individual (that is, they differ from other subjects and other situations), and this in turn means that the concretisation of the general premise, which depends logically on the descriptive lesser premises cannot be always identical - that is, it cannot be deductive reasoning. In other words, because an individual subject is a component of the empirical situation, his or her preferences must be taken into account in its description (as long as, of course, they are rational) - which in turn leads to the conclusion that he himself or she herself chooses an adequate description of the situation.

For the aforementioned reasons, neither the rationality of the content of desires nor the rationality of specific decisions can be based on the fact that they are strictly deduced from more general premises (including the absolutely first imperative premise), but only on the weaker relation of non-contradiction. It is also worth noting that if desires and decisions - in order to obtain the value of rationality - were to result by deduction from more general premises, it would lead to a very baffling conclusion about all practical rationality. It would mean that the only act of freedom is the primaeval decision - all the remaining "decisions" would essentially be a stoic consent to the individual links of chains of logical reasoning that, after all, have the attribute of necessity. The human subject would then be in a situation similar to that of Leibniz's God - he or she would indeed choose the existence in the world in which he or she was born, but because of the logical necessities that govern this world, he or she would not be able to choose anything else in it.

4) The criterion of realism and effectiveness. In addition to the positive primaeval decision (establishing the first imperative premise) and logical non-contradiction between the contents of desires, rationality of action also requires that both the desires of the subject and their specific selection performed in particular decisions should be shaped with a significant participation of the descriptive knowledge of the real world. Although descriptive knowledge does not justify desires 
and decisions, it is a criterion distinguishing the field of desires and rational decisions from the sphere of fantasy, dreams, and choices that "do not take reality into consideration." In the face of all the contents of desires and the arbitrary excess of imperative judgements, descriptive knowledge performs the function of "sifting the wheat from the chaff" - such knowledge exposes desires with unrealistic or mutually excluding contents, as well as unjustified imperatives, as irrational. The functions of descriptive knowledge for practical rationality are in general as follows: (a) only on its basis can we distinguish real possibilities from real impossibilities; (b) effectiveness of action, predicting its effects, or the appropriate counteraction against the incoming threats are not possible without knowledge of causal relations; (c) the subject's self-knowledge (which is also a kind of descriptive knowledge) constitutes the necessary information for him or her about what actions and states of affairs make him or her happy, to what extent, and which of them he or she should prefer over others; (d) and finally, empirical knowledge about each situation and its conditions allows to decide which of the rational desires should be realised and in which situation. The rationality of the desire which justifies a given act is only a necessary condition of the rationality of an act, but it is not a sufficient one. The features of the situation may be such that, for example, some rational desire has no chance of being realised (while in another it can be easily realised) or its effective realisation would have to violate many other values, and as a result, the balance of the results of this realisation would be negative. It may also be that the fulfilment of a rational desire in a given situation excludes a value higher than the value of that fulfilment - while in other situations both values would be reconcilable. In all of these examples of situations (and probably their other variants are also possible), the realisation of a given desire, although it is rational in terms of its logic - that is, it is non-contradictory with the content of the primaeval decision and the content of other desires - is irrational either because of ineffectiveness or because of unfavourable final balance. Both of these reasons, therefore, imply irrationality of action because they indicate a deficit in happiness, that is, a decrease in the very thing that was supposed to be sustained and increased as a result of the action. To sum up, practical rationality requires that its necessary condition in the form of rationality of desires themselves be supplemented with the sufficient condition in the form of rationality of the act. The criterion of the latter rationality comes from (with the former criterion met) the empirical knowledge of each situation.

5) The criterion of the hierarchy of values. In the colloquial version it may sound like this: do not confuse the means with the end or the soil with the crop. In the axiological discourse, in turn, it can be expressed as follows: the ontic hierarchy of basic and secondary elements is not identical to the hierarchy of values that these elements are entitled to. In other words, the fact that bodily life is the ontic basis of spiritual acts and creations does not lead to the conclusion that the values of bodily life are higher than those of spiritual life. In the human world, it is the ontically secondary layers of reality, such as the sphere of the spirit and culture, that have higher values, which in the axiological balance of one's life are far more important than the values of the body or social wellbeing. It is only in this spiritual sphere that a human being can obtain a happy fulfilment of his or her possibilities and the need for the meaning of life. Violating or ignoring this hierarchy in practical endeavours is therefore irrational, because it decreases the level of happiness of individuals and societies, and in the extreme and mass dimension it can even cause social pathologies and anomies (which was discussed not only by Emile Durkheim, but in a broader perspective also by Erich Fromm, or by Max Horkheimer in Critique of Instrumental Reason). The question of this hierarchy would require wider axiological explanations concerning a number of topics; the present article, however, has no space to provide them. ${ }^{9}$

Finally, it is worth mentioning the problems that the proposed approach suggests and which should be developed and analysed in detail.

First of all, it is the problem of mutual relations between practical and theoretical rationality. Focusing the discussion on the first one, I only marginally mentioned the most obvious differences between them, basically neglecting their common features and their interpenetration. However, this issue would require a more detailed investigation. It is not only theoretical knowledge - which I have already emphasised - that is necessary for practical rationality, but also vice versa: it seems that the sources and some elements of practical rationality form part of the foundations of theoretical rationality (confirming to some extent Immanuel Kant's claim about the primacy of 
practical reason over the theoretical). However, at the core of the practice of theoretical argumentation, there are, it seems, some important practical reasons which indicate not only values and goals, but also the conditions of scientific knowledge. ${ }^{10}$

The second problem that I had to omit is the issue of this sphere of practical reasons that creates the field of morality. Although this sphere is a subset and concretisation of the whole domain of axiology (and therefore subject to general rules of practical rationality), the specificity of its area of concern, which is limited to relations between subjects, would require a significant complementation of these general rules with rules governing only this - so to speak - practical moral sub-rationality. The most important difference between the moral sphere and the remaining area of axiology is that the conclusions of practical moral inferences cannot be relativised to the subject's individuality (moral obligations are universal), whereas in the non-moral axiological area, each set and hierarchy of values chosen for realisation are rational as long as they are adapted to each of the subject's individualities. Because, therefore, moral values are universal, and extra-moral values are relativised to subjective differences, the realisation of the latter on the part of every subject would be rational only if it did not violate moral values. I analysed the issue of argumentation required in ethics itself in other articles [8, pp. 211-270]

The third issue, which should - perhaps - be thoroughly examined and developed, is an attempt at logical formalisation concerning the rationality of the act (referred to in criterion 4). This formalisation, if it were successful, would unambiguously establish what kind of logical relations between imperative and descriptive judgements are required to make a given act practically rational in a given situation. It would therefore be an improved version - if it is possible at all - of the practical syllogism.

\section{References}

1. Apel, K.-O. Transformation der Philosophie, Frankfurt am Main: Suhrkamp, 1973, vol. 2.

2. Chmielecki, A. Rozum i racjonalność - rozważania esencjalne, In A. Chmielecki (ed.), Rozum i przestrzenie racjonalności, Gdańsk: Wydawnictwo Uniwersytetu Gdańskiego, 2010, pp. 11-56.

3. Kleszcz, R. O racjonalności. Studium epistemologiczno-metodologiczne, Łódź: Wydawnictwo Uniwersytetu Łódzkiego, 1998.

4. Kopciuch, L. Wolność a wartości. Max Scheler, Nicolai Hartmann, Dietrich von Hildebrand, Hans Reiner, Lublin: Wydawnictwo UMCS, 2010.

5. Rozprawa metafizyczna, transl. by S. Cichowicz, In G. W. Leibniz, Wyznanie wiary filozofa, transl. by various authors, Warszawa: Wydawnictwo Naukowe PWN, 1969.

6. MacIntyre, A. Dziedzictwo cnoty. Studium z teorii moralności, transl. by A. Chmielewski, Warszawa: Wydawnictwo Naukowe PWN, 1996.

7. Morawiec, E. Wybrane filozoficzne koncepcje rozumu ludzkiego i racjonalności, Warszawa: Wydawnictwo Liberi Libri, 2014.

8. Niemczuk, A. Filozofia praktyczna. Studia i szkice, Lublin: Wydawnictwo UMCS, 2016.

9. Niemczuk, A. Kolista struktura praktyki. Rozważania metapraktyczne, In A. Niemczuk, Filozofia praktyczna. Studia i szkice, Lublin: Wydawnictwo UMCS, 2016, pp. 126-131.

10. Niemczuk, A. O poznaniu wartości, In A. Niemczuk, Filozofia praktyczna. Studia i szkice, Lublin: Wydawnictwo UMCS, 2016, pp. 87-98.

11. Niemczuk, A. Stosunek wartości do bytu. Dociekania metafizyczne, Lublin: Wydawnictwo UMCS, 2005.

12. Niemczuk, A. Traktat o złu, Lublin: Wydawnictwo UMCS, 2013.

13. Schnadelbach, H. Racjonalność i uzasadnianie, In T. Buksiński (ed.), Rozumność $i$ racjonalność, Poznań: Wydawnictwo Naukowe IF UAM, 1997, pp. 37-50.

14. Szarfenberg, R. Podstawy $i$ granice racjonalizacji polityki spolecznej, http://rszarf.ips.uw.edu.pl/pdf/doktorat_calosc.pdf (12.07.2019), especially chapter 3: Racjonalność i racjonalizacja, pp. 111-196.

15. Sztombka, W. Karla Otto Apla koncepcja dyskursu i uzasadnienia moralności, In J. Ziobrowski (ed.), Etyka u schytku drugiego tysiaclecia, Warszawa: Wydawnictwo Naukowe SCHOLAR, 2013, pp. 122-149. 
16. Tałasiewicz, M. O pojęciu racjonalności, part I and II, Filozofia nauki 1-2, 1995, pp. 79-100; 3, pp. 39-57.

17. Życiński, J. Granice racjonalności, Warszawa: Wydawnictwo Petrus, 1993.

18. Życiński, J. Teizm i filozofia analityczna, vol. 1, Kraków: Wydawnictwo "Znak”, 1985.

\section{Notes}

1. The identity of the concepts of "rationality" and "functioning of reason" as far as their scope is concerned is assumed, it seems, by Herbert Schnadelbach [13].

2. I wrote in more detail about practice in [9, pp. 126-131].

3. I presented a detailed critique of both subjectivist and objectivist understanding of values in [11, pp. 175-200].

4. I described and commented on this syllogism in [11, pp. 283-288].

5. Such an example of a reason which is correct and probably most often used is in fact very simple and is as follows: because I have a desire for pleasure $\mathrm{X}$, and there are no practical reasons that would not allow it (i.e. pleasure $\mathrm{X}$ does not conflict with more important values), I choose pleasure $\mathrm{X}$.

6. E.g. Andrzej Chmielecki understands the principles of rationality in the following way: "Like the principles of logic, also the principles of rationality cannot be derived from something else - they are the immanent laws of the functioning of the subject's spiritual acts, belonging to the set of the first principles. They can only be determined a priori, by means of relevant essential analyses. Thus, they are something generally valid, universal, independent of any individual subject. The subject acts rationally if he or she 'participates' in them [...] (if his or her acts are compatible with them); he or she does not need to know them explicitly, however" [2, pp. 47-48].

7. I wrote about the significance of self-knowledge for axiological knowledge in [10, pp. 87-98].

8. The suitability of this judgement lies in the fact that its content has to be related with the content of the general premise, e.g. "You should help your friends" (greater imperative premise). "Adam is a friend and needs help" (lesser descriptive premise). "Adam should be helped" (an imperative individual conclusion).

9. Nicolai Hartmann with Max Scheler were involved in an interesting discussion about the hierarchy of values and dependencies between higher and lower values [4, pp. 77-89].

10. Broad and significant argumentation in support of the claim about the necessary normative conditions of theoretical knowledge has been presented in modern times by Karl-Otto Apel [1], [14]. 